\title{
REGENERAÇÃO NATURAL DE Ocotea odorifera (VELL.) ROHWER (LAURACEAE) EM FLORESTA OMBRÓFILA MISTA, PARANÁ, BRASIL
}

\author{
NATURAL REGENERATION OF Ocotea odorifera (VELL.) ROHWER (LAURACEAE) IN \\ ARAUCARIA FOREST, PARANÁ STATE, BRAZIL
}

\author{
Larissa Amanda Bett ${ }^{1}$ Dayane May ${ }^{2}$
}

\begin{abstract}
RESUMO
A limitação do conhecimento sobre a autoecologia de Ocotea odorifera (Lauraceae) nos remanescentes conservados indica a necessidade do desenvolvimento de pesquisas que forneçam subsídios para a implantação de programas de conservação. Nesse contexto, a presente pesquisa teve como objetivo avaliar a regeneração natural de Ocotea odorifera (Lauraceae), espécie ameaçada de extinção, característica da fitofisionomia Floresta Ombrófila Mista (FOM) ocorrente na Reserva Particular do Patrimônio Natural (RPPN) Uru, Lapa, Paraná, Brasil. A distribuição nacional dessa espécie foi levantada a partir de dados museológicos disponíveis em acervos online, e no Museu Botânico de Curitiba (MBM). Para análise da regeneração natural foram definidas 10 parcelas circulares com $40 \mathrm{~m}$ de diâmetro, contendo uma matriz de sementes no centro, totalizando $12.560 \mathrm{~m}^{2}$ de área amostral. Todos os indivíduos regenerantes de Ocotea odorifera contidos nas parcelas foram georreferenciados e mensurados em altura e Diâmetro a Altura do Solo (DAS). Foi medida também a espessura de serapilheira e intensidade luminosa em cada parcela. As análises foram baseadas nos parâmetros fitossociológicos e o grau de dispersão da espécie foi avaliado por meio do Índice de Morisita (Id). O levantamento museológico revelou 867 registros de Ocotea odorifera, compilados em 47 coleções, com ocorrência em 16 estados brasileiros. A densidade da regeneração natural foi de 77,6 ind.ha- ${ }^{-1}$ e o padrão de crescimento da regeneração natural demonstrou tendência para J-invertido, com maior abundância de indivíduos $(44,7 \%)$ com altura até $0,50 \mathrm{~m}$. A presença das árvores-matrizes na RPPN Uru esteve restrita às áreas de FOM em estágio avançado de sucessão, sendo que as unidades amostrais com serapilheira mais espessa foram aquelas com maior número de indivíduos mensurados. $\mathrm{O}$ reconhecimento das potencialidades ecológicas, especialmente quanto à capacidade regenerativa e os fatores que a influenciam em ambiente natural, atuam como base para ações conservacionistas que garantem a perpetuação da Ocotea odorifera.
\end{abstract}

Palavra-chave: autoecologia; conservação; distribuição espacial; canela-sassafrás.

\begin{abstract}
The limitation of knowledge about auto-ecology of Ocotea odorifera (Lauraceae) in the preserved remnants indicates the need for further research to provide subsidies for the implementation of conservation programs. In this context, the present study aimed to evaluate the natural regeneration of Ocotea odorifera (Lauraceae), an endangered species, characteristic of the vegetation type of Araucaria Forest (FOM) occurring in Private Natural Heritage Reserve (PRNP) Uru, Municipality of Lapa, Paraná state, Brazil. The national distribution of this species was lifted from museum collections of the available online data, and in the Curitiba Botanical Museum (MBM). To analyze the natural regeneration were set 10 circular plots of $40 \mathrm{~m}$ in diameter, containing an array of seeds in the center, totaling $12,560 \mathrm{~m}^{2}$ sampling area. All regenerating individuals Ocotea odorifera contained in the plots were geo-referenced and measured their height and Diameter at Ground Height (DGH). It was also measured the thickness of litter and light intensity in each plot.

1 Bióloga, Mestre em Biotecnologia Industrial, Universidade Positivo, Rua Prof. Pedro Viriato Parigot de Souza, 5300, CEP 81280-330, Curitiba (PR), Brasil. larissabett@hotmail.com

2 Bióloga, Dr, Professora de Ciências Biológicas Universidade Positivo, Rua Prof. Pedro Viriato Parigot de Souza, 5300, CEP 81280-330, Curitiba (PR), Brasil. dayanemay@hotmail.com
\end{abstract}


Analyses were based on phytosociological parameters and the degree of species dispersion was assessed by Morisita Index (Id). The museum survey found 867 records Ocotea odorifera, compiled by 47 national collections, occurring in 16 Brazilian states. The density of natural regeneration was 77.6 ind.ha $^{-1}$ and the growth pattern of population-inverted $\mathrm{J}$, with greater abundance of individuals (44.71\%) with heights up to $0.50 \mathrm{~m}$. The presence of seed trees in the PRNP Uru was limited to areas of FOM at an advanced stage of succession, and the sampling units with thicker litter were those with the highest number of measured individuals. The recognition of ecological potential, especially as the regenerative capacity and the factors influencing it in a natural environment, act as a basis for conservation actions to ensure the perpetuation of Ocotea odorifera.

Keywords: autoecology; conservation; spatial distribution; canela-sassafrás.

\section{INTRODUÇÃO}

A cobertura do bioma Mata Atlântica corresponde a 13,04\% do território brasileiro, ocupando uma área de 11.110.182 $\mathrm{km}^{2}$, que se estende ao longo da costa litorânea, desde o Estado do Rio Grande do Norte até o Rio Grande do Sul (INSTITUTO BRASILEIRO DE FLORESTAS, 2014). Os fragmentos remanescentes se apresentam como um mosaico com extensas áreas degradadas permeadas por pequenas áreas conservadas, distribuídas principalmente nas regiões sul e sudeste (ZAÚ, 1998; FRANKE et al., 2005). Estima-se que apenas 7\% da cobertura original da Mata Atlântica permaneça conservada, sendo considerado uma das regiões com maior biodiversidade e uma das mais ameaçadas do mundo (MYERS et al., 2000; GALINDO-LEAL; CÂMARA, 2005).

A Mata Atlântica é composta por diferentes fitofisionomias, entre elas a Floresta Ombrófila Mista (FOM) ou Floresta com Araucária, que é caracterizada como um ambiente estruturalmente complexo que abriga diversas comunidades biológicas (NASCIMENTO; LONGHI; BRENA, 2001). No Paraná, a FOM recobria originalmente uma área correspondente a $37 \%$ da superfície do estado, estando restrita aos remanescentes segmentados que conservam apenas $0,8 \%$ da cobertura original (CASTELA; BRITEZ, 2004). Dentre as espécies que contribuem para a caracterização dessa fitofisionomia florestal encontra-se a Ocotea odorifera (Vell.) Rohwer (canela-sassafrás) (SANTA-CATARINA; MACIEL; PEDROTTI, 2001; DALMASO et al., 2013), que apresenta um amplo histórico de exploração devido ao seu valor madeireiro e farmacêutico, o que resultou na inclusão da espécie nas listas de ameaçadas de extinção do Paraná e do Brasil (OBRZUT; CARVALHO, 2001; INSTITUTO AMBIENTAL DO PARANÁ, 2008; BRASIL, 2014).

Ocotea odorifera é uma espécie perenifólia, heliófita e aromática originária da Mata Atlântica e endêmica do Brasil (SANTA-CATARINA; MACIEL; PEDROTTI, 2001; LORENZI, 2008; DALMASO et al., 2013) que apresenta entre 8 e $25 \mathrm{~m}$ de altura, com tronco tortuoso (LORENZI, 2008). Apresenta inflorescências paniculadas terminais, composta por flores pequenas, hermafroditas, perfumadas e de coloração branco-amarelada (LORENZI; MATOS, 2002). Os frutos são envolvidos por uma cúpula e possuem cerca de $2,0 \mathrm{~cm}$ de comprimento por $1,3 \mathrm{~cm}$ de diâmetro enquanto os diásporos possuem $1,2 \mathrm{~cm}$ de comprimento por $0,9 \mathrm{~cm}$ de largura, com cotilédones crassos e superfície lisa, encerrando uma pequena plúmula e radícula (CETNARSKI-FILHO; NOGUEIRA, 2005). As folhas são elípticas e obovadas, lanceoladas a oblanceoladas, glabras, apresentando de 7 a $14 \mathrm{~cm}$ de comprimento (LORENZI, 2008).

A floração e frutificação ocorrem em diferentes épocas do ano (QUINET; ANDREATA, 2002; BROTTO; CERVI; SANTOS, 2013), com predomínio nos meses de agosto-setembro e abril-julho, respectivamente. $\mathrm{O}$ estabelecimento de associações simbióticas com fungos micorrízicos arbusculares deve ocorrer para o desenvolvimento ideal, o que dificulta o manejo de mudas, uma vez que a retirada do substrato impede a interação entre a planta e o fungo (CARVALHO, 2005).

Distribui-se desde o sul da Bahia até o Rio Grande do Sul, nos biomas Amazônia, Cerrado e Mata Atlântica. A maior concentração encontra-se na região sul, com ampla distribuição no Estado do Paraná, ocorrendo com maior representatividade na Floresta Ombrófila Mista e Floresta Ombrófila Densa (CETNARSKI-FILHO; NOGUEIRA, 2005; BROTTO; CERVI; SANTOS, 2013; DALMASO et al., 2013; QUINET et al., 2014).

A espécie foi amplamente explorada devido à produção do óleo essencial volátil, cujo principal componente químico é o safrol, utilizado na fabricação de inseticidas, cosméticos e produtos farmacêuticos 
(DALMASO et al., 2013), principalmente medicamentos com propriedades sudoríficas, antirreumáticas, antissifilíticas e diuréticas (CASTELLANI et al., 2006). A exploração teve seu ápice nas décadas de 40 a 70 (SANTA-CATARINA; MACIEL; PEDROTTI, 2001), que aliada à ausência de aplicação de técnicas adequadas de manejo, levou à progressiva diminuição das populações e à consequente inclusão da espécie na lista de ameaçadas de extinção do Brasil e Paraná. A produção irregular de sementes, o grande distanciamento entre as árvores, a redução das populações dos agentes polinizadores e dispersores e o baixo vigor das sementes são as maiores ameaças à perpetuação da Ocotea odorifera (CARVALHO, 2005). Atualmente, o uso para fins comerciais encontra-se restrito por lei, sendo permitido somente em casos excepcionais como obras de utilidade pública ou retirada de indivíduos que representem risco à integridade de patrimônios públicos, particulares ou à vida humana (DALMASO et al., 2013).

Em florestas tropicais, a dinâmica e estrutura das comunidades e populações arbóreas se apresentam como um reflexo da perturbação histórica e das pressões antrópicas, uma vez que as mudanças na densidade de indivíduos são fortemente influenciados por fatores ambientais bióticos e abióticos (MACHADO et al., 2010). O desenvolvimento das florestas é analisado pela distribuição de idades, inferidas a partir do tamanho, pelos padrões de distribuição e pelos processos de dispersão dos organismos, representado pela regeneração natural (CALDATO; LONGHI; FLOSS, 1999; VENTUROLI; FELFILI; FAGG, 2011).

A regeneração natural representa um mecanismo importante para a sobrevivência, desenvolvimento e manutenção dos ecossistemas florestais, indicando o potencial de recrutamento de novos indivíduos. Constitui um aspecto efetivo para diagnosticar a conservação do fragmento e a sua resposta frente a perturbações naturais ou antrópicas, sendo um elemento-chave para a preservação, conservação e recuperação das florestas (SILVA et al., 2007; PALUDO; MANTOVANI; REIS, 2011).

A partir do conhecimento de aspectos da regeneração, podem ser identificadas as potencialidades e possibilidades para a criação de estratégias de manejo em prol de um sistema sustentável (VAN GROENENDAEL; BULLOCK; PEREZ-JIMENEZ, 1996). A geração, recuperação e sistematização dos conhecimentos sobre a Ocotea odorifera atuam como uma ferramenta na implantação de programas de conservação e manejo que garantam a perpetuação e visem diminuir o risco de extinção.

Sob essa perspectiva, a presente pesquisa tem como o objetivo avaliar a regeneração natural da Ocotea odorifera (Lauraceae) na Reserva Particular do Patrimônio Natural (RPPN) Uru, Município da Lapa, Paraná, Brasil.

\section{MATERIAL E MÉTODOS}

\section{Área de estudo}

A Reserva Particular do Patrimônio Natural (RPPN) Uru é a Unidade de Conservação contemplada na presente pesquisa. O fragmento de 128,67 ha de área conservada está localizado no município da Lapa,

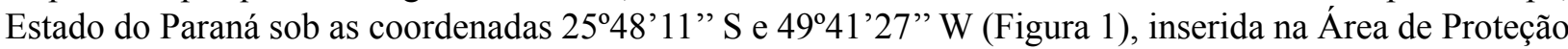
Ambiental (APA) da Escarpa Devoniana. Situa-se na região geográfica do Segundo Planalto Paranaense na região fisiográfica dos Campos Gerais, embora apresente características de Primeiro Planalto (INSTITUTO CHICO MENDES DE CONSERVAÇÃO DA BIODIVERSIDADE, 2014). Sua criação foi formalizada pelo Decreto $\mathrm{n}^{\circ} 1922$, de 5 de junho de 1996 e tem como objetivo assegurar a proteção do limite natural entre os planaltos paranaenses e locais de beleza cênica e vestígios arqueológicos e pré-históricos (INSTITUTO CHICO MENDES DE CONSERVAÇÃO DA BIODIVERSIDADE, 2014).

A cobertura vegetal da área é caracterizada como Floresta Ombrófila Mista (FOM), com manchas de Estepe Gramíneo-lenhosa, representando um remanescente importante para a manutenção dos ecossistemas pela presença de um ecótono (LEITE; KLEIN, 1990; IBGE, 2012; KOZERA et al., 2012). Possui conectividade com o entorno, especialmente com o Parque Estadual do Monge, Unidade de Conservação de 333 ha limítrofe à RPPN Uru.

Está inserida na bacia hidrográfica do rio Iguaçu, dando origem a nascentes e pequenos riachos que são drenados em direção ao rio da Estiva, um dos tributários do rio da Várzea, que constituiu um dos principais afluentes do rio Iguaçu (INSTITUTO CHICO MENDES DE CONSERVAÇÃO DA BIODIVERSIDADE, 2014). 
O clima da região, segundo a classificação de Köppen, é do tipo Cfb - clima temperado úmido com verão temperado, apresentando inverno seco e com geadas e verão fresco e úmido com chuvas distribuídas uniformemente ao longo do ano. $\mathrm{O}$ mês mais quente é fevereiro, com temperatura média de $22^{\circ} \mathrm{C}$ e o mês mais frio é julho, com temperatura média de $18^{\circ} \mathrm{C}$. O município da Lapa apresenta um regime de chuvas de $1.200 \mathrm{~mm}$ a $1.360 \mathrm{~mm}$ ao ano, sendo o mês de agosto o mais seco (INSTITUTO CHICO MENDES DE CONSERVAÇÃO DA BIODIVERSIDADE, 2014).

O solo da área de estudo é caracterizado como Cambissolo Háplico Tb Distrófico, com argila de alta atividade e baixa saturação por bases. Devido à heterogeneidade de sua origem, suas características como drenagem e profundidade apresentam grande variação de um local para outro. Nas áreas de entorno é possível encontrar Neossolos, caracterizados por apresentar menos de $20 \mathrm{~cm}$ de espessura, com pouca alteração do material de origem, mineral ou orgânico, devido à resistência ao intemperismo ou pela baixa atuação dos processos pedogenéticos (INSTITUTO CHICO MENDES DE CONSERVAÇÃO DA BIODIVERSIDADE, 2014).

\section{Coleta dos dados}

A distribuição da espécie foi avaliada com base nos registros museológicos nacionais, obtidos por meio do Centro de Referência em Informação Ambiental (CRIA), que forneceu dados para a análise comparativa da distribuição da espécie no Brasil, especialmente na região sul. Os registros da espécie para o município da Lapa e região foram levantados a partir dos registros no Museu Botânico Municipal de Curitiba (MBM).

A metodologia empregada para análise da regeneração natural foi uma adaptação da utilizada por Cetnarski-Filho e Nogueira (2004), com a definição de 10 parcelas circulares com $40 \mathrm{~m}$ de diâmetro, o que correspondeu a $12.560 \mathrm{~m}^{2}$ (1,26 ha) de área amostral, estabelecidas na área de estudo de acordo com a presença de árvores-matrizes de sementes (Figura 1A). O centro da parcela foi definido como o tronco central da árvore-matriz, a partir do qual foram demarcados os quatro eixos principais norte-sul e lesteoeste, formando quatro quadrantes. Em cada quadrante, foram estabelecidos cinco raios consecutivos de quatro metros, totalizando $20 \mathrm{~m}$ de raio (Figura 1B).

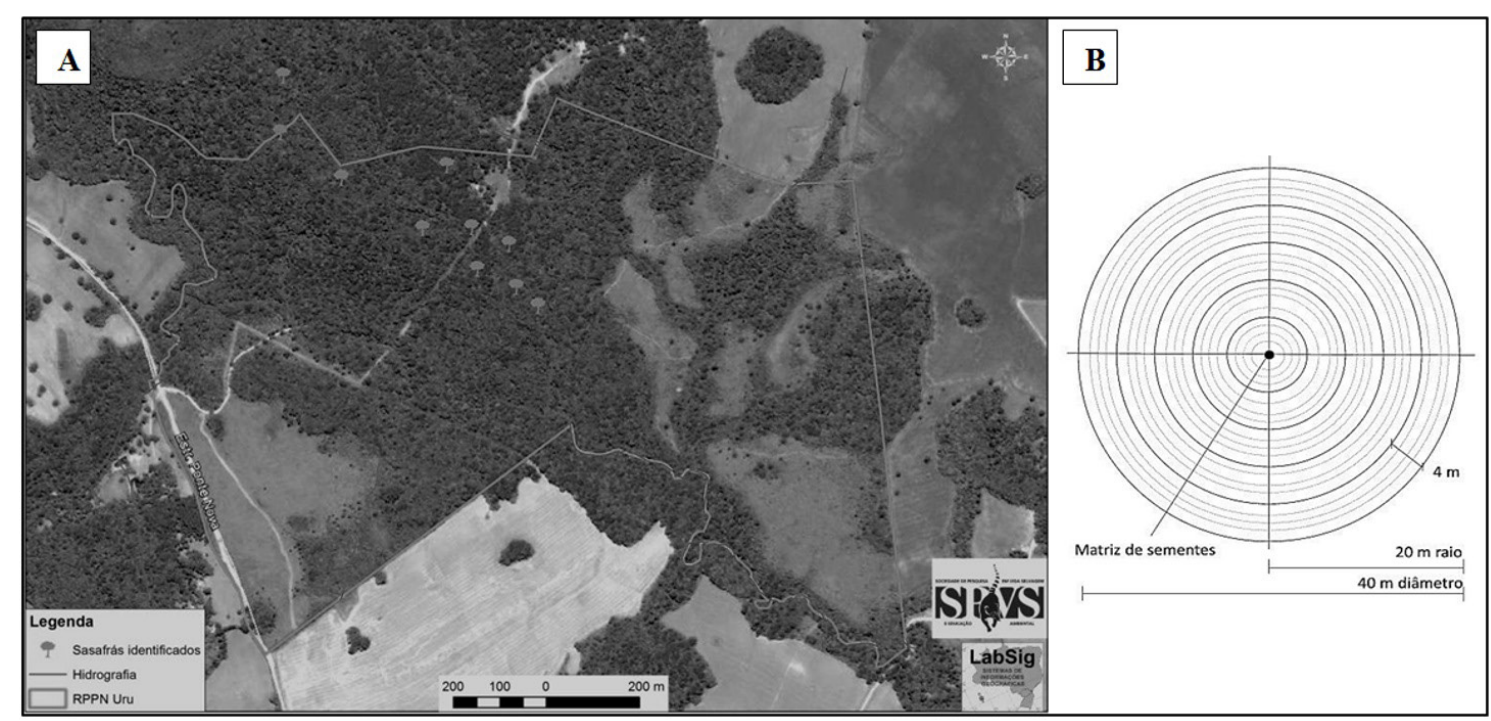

FIGURA 1: Unidades amostrais da regeneração natural de Ocotea odorifera na RPPN Uru, município da

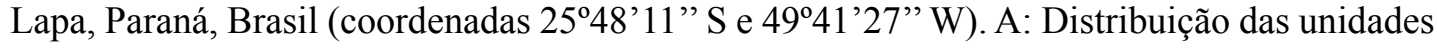
amostrais na área de estudo. B: Esquematização das parcelas.

FIGURE 1: Sample units of natural regeneration of Ocotea odorifera in the Uru PNHR, Lapa, Paraná state, Brazil (coordinates $25^{\circ} 48^{\prime} 11^{\prime \prime S}$ e $49^{\circ} 41^{\prime} 27^{\prime \prime} \mathrm{W}$ ). A: Distribution of sample units in the study area. B: Schematic of the plots. 
Para os indivíduos com até $2 \mathrm{~m}$ de altura foram mensurados a altura e diâmetro a altura do solo (DAS) com auxílio de fita métrica e paquímetro e a localização na parcela foi estimada por meio da marcação em papel milimetrado. Foi mensurada a altura e o perímetro a altura do peito (PAP) das árvores-matrizes de sementes, e a área de projeção da copa foi estimada com a marcação em papel milimetrado a cada $45^{\circ}$ em relação ao tronco central. A espessura da serapilheira foi mensurada em centímetros e a luminosidade foi medida em lux com luxímetro CIluminar, ambos em cinco repetições por parcela, as quais geraram um valor médio. As medições de luminosidade ocorreram em um único dia em um intervalo de duas horas, evitando divergências de acordo com as condições climáticas e a espessura da serapilheira foi medida a dois metros de distância do tronco central, em cinco direções. Os indivíduos amostrados foram classificados em quatro classes etárias de acordo com a altura, seguindo o proposto por Caldato, Longhi e Floss (1999): 1) Juvenil I ( 0 a $0,50 \mathrm{~m}$ de altura); 2) Juvenil II (0,51 a $1 \mathrm{~m}$ de altura); 3 ) Juvenil III (1 a 1,5 $\mathrm{m}$ de altura); e 4) Juvenil IV (1,5 a $2 \mathrm{~m}$ de altura).

\section{Análise dos dados}

O grau de dispersão de Ocotea odorifera na área foi obtido por meio da utilização do Índice de Morisita (Id) (KREBS, 1999), que apresenta qualidade na detecção do grau de dispersão para amostras que variam em número de indivíduos e média, expressando seus resultados de 0 a 1 , indicando distribuição aleatória e agrupamento máximo, respectivamente.

Foram considerados os parâmetros fitossociológicos (MUELLER-DOMBOIS; ELLENBERG, 1974), tais como o número de indivíduos e densidade, e abióticos representados pela serapilheira e luminosidade. Para a análise estatística, utilizaram-se os testes de ANOVA, Tukey e correlação linear de Pearson (r), feitos com auxílio do software SPSS Statistics 17.0 Softonic ${ }^{\circledR}$. O teste de ANOVA teve como função comparar, em termos probabilísticos, as médias dos parâmetros mensurados das populações submetidas à amostragem, considerando um nível de significância $\alpha=0,05(5 \%)$. O coeficiente de correlação linear de Pearson $(r)$ foi utilizado para verificar a relação entre as variáveis fitossociológicas e ambientais analisadas e a influência de uma sobre a outra.

\section{RESULTADOS E DISCUSSÃO}

\section{Distribuição}

Existem, atualmente, 867 registros de Ocotea odorifera compilados em 47 coleções nacionais. A ocorrência da espécie está confirmada em 216 municípios brasileiros, distribuídos em 16 Estados, sendo São Paulo o estado com maior representatividade (197), seguido por Minas Gerais (177), Santa Catarina (155) e Paraná (143). Os demais estados apresentaram menos de 100 registros cada, com destaque para o Pará e Rio Grande do Norte, com apenas um (CENTRO DE REFERÊNCIA EM INFORMAÇÃO AMBIENTAL, 2014). Os dados museológicos apontaram o predomínio da ocorrência da espécie nas regiões litorâneas, caracterizadas pelo domínio do bioma Mata Atlântica, com destaque para as regiões sul e sudeste. No Museu Botânico de Curitiba constaram 81 registros de Ocotea odorifera oriundas do sul do Brasil, com predomínio de distribuição nos Estados do Paraná e Santa Catarina. Das 81 exsicatas, 46 têm coletas no Paraná, e apenas uma no município da Lapa, datada em 1974. A distribuição no Estado demonstra maior concentração na região leste, onde se encontra estabelecida a Floresta Ombrófila Mista e Floresta Ombrófila Densa (CARVALHO, 2005; BROTTO; CERVI; SANTOS, 2013).

\section{Regeneração natural}

Nas 10 parcelas analisadas foram mensurados 2.033 indivíduos de Ocotea odorifera oriundos da regeneração natural. A densidade média foi de $0,16 \mathrm{ind} . / \mathrm{m}^{2}(77,6 \mathrm{ind} / \mathrm{ha})$, sendo que a parcela mais numerosa apresentou 438 regenerantes e densidade de $0,34 \mathrm{ind} / \mathrm{m}^{2}$ (164,9 ind/ha), e a menos numerosa $0,005 \mathrm{ind} / \mathrm{m}^{2}(2,4 \mathrm{ind} / \mathrm{ha})$, com seis regenerantes mensurados. As árvores-matrizes de sementes selecionadas apresentaram 16,4 $\mathrm{m}$ de altura média e PAP médio de 136,8 $\mathrm{cm}$ (Tabela 1). 
TABELA 1: Altura e perímetro a altura do peito (PAP) das árvores-matrizes de Ocotea odorifera, seguida pelo seu número de indivíduos, altura, diâmetro a altura do solo (DAS) e densidade dos regenerantes, espessura da serapilheira e intensidade luminosa nas dez parcelas amostradas na RPPN Uru, Lapa, Paraná, Brasil. * Caules ramificados.

TABLE 1: Height and Circumference at Breast Height (CBH) of Ocotea odorifera matrix, number of individuals, height, Diameter Ground Height (DGH) and density of regenerating, litter thickness and light intensity in the ten plots sampled in PNHR Uru, Lapa, Paraná state, Brazil. * Branched stems.

\begin{tabular}{lcccccccc}
\hline & \multicolumn{3}{c}{ Árvore-matriz } & \multicolumn{3}{c}{ Regeneração } & \multicolumn{3}{c}{ Abióticos } \\
\cline { 2 - 8 } Parcela & $\begin{array}{c}\text { Altura } \\
(\mathrm{m})\end{array}$ & PAP $(\mathrm{cm})$ & N. ind. & $\begin{array}{c}\text { Altura } \\
\text { média } \\
(\mathrm{cm})\end{array}$ & $\begin{array}{c}\text { DAS } \\
\text { médio } \\
(\mathrm{cm})\end{array}$ & $\begin{array}{c}\text { Densidade } \\
\left(\mathrm{ind} / \mathrm{m}^{2}\right)\end{array}$ & $\begin{array}{c}\text { Serapilheira } \\
(\mathrm{cm})\end{array}$ & $\begin{array}{c}\text { Luz } \\
(\text { lux })\end{array}$ \\
\hline 1 & 15,0 & 130,0 & 20 & 48,2 & 0,46 & 0,02 & 3,1 & 282,98 \\
2 & 17,0 & 216,0 & 6 & 114,0 & 0,65 & 0,005 & 2,8 & 294,17 \\
3 & 14,0 & 104,0 & 438 & 72,6 & 1,01 & 0,35 & 5,8 & 301,64 \\
4 & 18,0 & 118,0 & 413 & 79,4 & 0,70 & 0,33 & 7,2 & 288,93 \\
5 & 15,0 & 210,0 & 216 & 44,9 & 0,50 & 0,17 & 4,3 & 282,68 \\
6 & 17,0 & $36,0+115,0+140,0+202,0^{*}$ & 280 & 63,6 & 0,63 & 0,22 & 4,9 & 295,83 \\
7 & 16,0 & $108,0+119,0+137,0^{*}$ & 297 & 53,4 & 0,54 & 0,24 & 5,0 & 301,62 \\
8 & 15,0 & $122,0+49,0^{*}$ & 80 & 47,7 & 0,44 & 0,06 & 4,7 & 329,93 \\
9 & 22,0 & 202,0 & 222 & 69,9 & 0,61 & 0,18 & 3,6 & 299,42 \\
10 & 15,0 & $109,0+76,0+170,0^{*}$ & 61 & 69,9 & 0,73 & 0,05 & 1,8 & 263,46 \\
Média & 16,4 & 136,83 & 204,1 & 66,4 & 0,63 & 0,16 & 4,3 & 294,07 \\
\hline
\end{tabular}

O teste de ANOVA apontou diferença significativa $(P=0,019)$ no que diz respeito às médias obtidas para as parcelas amostradas, comprovado ainda por meio do teste post-hoc de Tukey.

A distribuição das árvores-matrizes de sementes e regeneração natural na RPPN Uru esteve restrita à Floresta Ombrófila Mista em estágio avançado de sucessão, não sendo observada a ocorrência da espécie nas áreas de Estepe Gramíneo-lenhosa e em estágios sucessionais médio e inicial. A constatação concorda com o proposto por Carvalho (2005), que classifica Ocotea odorifera como uma espécie secundária tardia ou clímax.

A espessura média da serapilheira foi de $4,3 \mathrm{~cm}$, sendo que as unidades amostrais com serapilheira mais espessa foram aquelas em que a regeneração natural foi mais expressiva. A correlação linear de Pearson $(r)$, com valor de $r=0,85(P=0,002)$, indicou correlação entre a espessura da serapilheira e o número de indivíduos regenerantes. As parcelas com maior número de regenerantes não foram influenciadas pela luminosidade, que apresentou média de 294,07 lux, demonstrando pouca influência deste fator abiótico na distribuição da regeneração, o que também é corroborado pelo valor de correlação de Pearson, com valor $r$ $=0,14(P=0,696)$.

A análise quantitativa dos fatores abióticos sobre a regeneração natural na área de estudo revelou que a espessura da serapilheira influenciou na abundância dos regenerantes e que não houve correlação estatisticamente significativa entre a intensidade luminosa e a densidade de indivíduos mensurados. Tais resultados confrontam com o descrito por Cetnarski-Filho e Nogueira (2004) em estudo desenvolvido com a regeneração natural da Ocotea odorifera em Tijucas do Sul - PR, em que a espessura da serapilheira não influenciou na regeneração natural. Os autores justificam a variação de abundância de indivíduos entre as parcelas, pela possível interferência de fatores como água, declividade e predação por animais, porém, não foi feita análise quantitativa de tais parâmetros.

Foi possível constatar um padrão ambiental para as unidades amostrais com maior abundância de indivíduos, que fornecem um ambiente úmido e com grande quantidade de matéria orgânica em decomposição. De acordo com Pereira et al. (2013), o processo de decomposição promovido pela atividade 
microbiana tem relação direta com a composição química do solo, o que fornece as condições adequadas para a germinação e desenvolvimento da Ocotea odorifera. Carvalho (2005) indica a necessidade da investigação da presença de fungos micorrízicos nas raízes de Ocotea odorifera, evidenciando uma possível dependência entre o desenvolvimento e a presença destes organismos. Os indivíduos regenerantes apresentaram-se mais abundantes nas regiões com grande quantidade e variedade de fungos, especialmente os basidiomicetos, observáveis em campo. A associação estabelecida entre os fungos e a Ocotea odorifera representa um nicho de pesquisa a ser explorado, visando à otimização da conservação da espécie e ampliação das possibilidades de cultura in vitro.

A estimativa da posição em relação ao centro da parcela permitiu constatar um acréscimo no número de juvenis conforme aumento da distância do tronco central (Figura 2).

A altura e PAP das árvores-matrizes de sementes não influenciaram na regeneração natural, uma vez que parcelas contendo indivíduos de mesmo porte apresentaram número de indivíduos variáveis e a maior parte (77\%) dos regenerantes foi encontrada fora da área de projeção da copa.

$\mathrm{O}$ aumento no número de plantas encontradas nas áreas mais distantes do centro da parcela indica um possível efeito de escape de predação junto à planta-matriz (NASCIMENTO; CARVALHO; LEÃO, 2002), tentativas de dispersão, o que evita a competição intraespecífica e possibilita a colonização de novos ambientes (SANTOS et al., 2011), além de associações micorrízicas diferenciadas (CARVALHO, 2005). Os mecanismos de dispersão são diretamente influenciados pelas variações morfológicas das sementes, determinando a distância a que podem ser dispersas e, consequentemente, a distribuição dos novos indivíduos (SALM, 2005).

Segundo Janzen (1970), a redução das populações de dispersores nas florestas da América do Sul acarretam na diminuição do espectro de dispersão das sementes, acarretando na germinação próxima a planta-matriz, na qual a taxa de mortalidade é alta. Em fragmentos conservados, como a RPPN Uru, tal realidade é atenuada pelo suporte ambiental fornecido às populações de dispersores, o que é potencializado pela conectividade estabelecida com o entorno. A presença dos corredores ecológicos permite diferentes categorias de proteção e manejo (BRASIL, 2007; BROCARDO; CÂNDIDO JÚNIOR, 2012), evidenciando a necessidade do desenvolvimento de pesquisas que forneçam subsídios para a implantação de ações de conservação.

O Índice de Morisita obtido foi de 1,16, indicando um padrão de distribuição do tipo agregado, o que corrobora os estudos de Cetnarski-Filho e Nogueira (2004), no qual observaram este mesmo padrão para Ocotea odorifera em Floresta Ombrófila Mista alterada com a retirada de madeira na década de

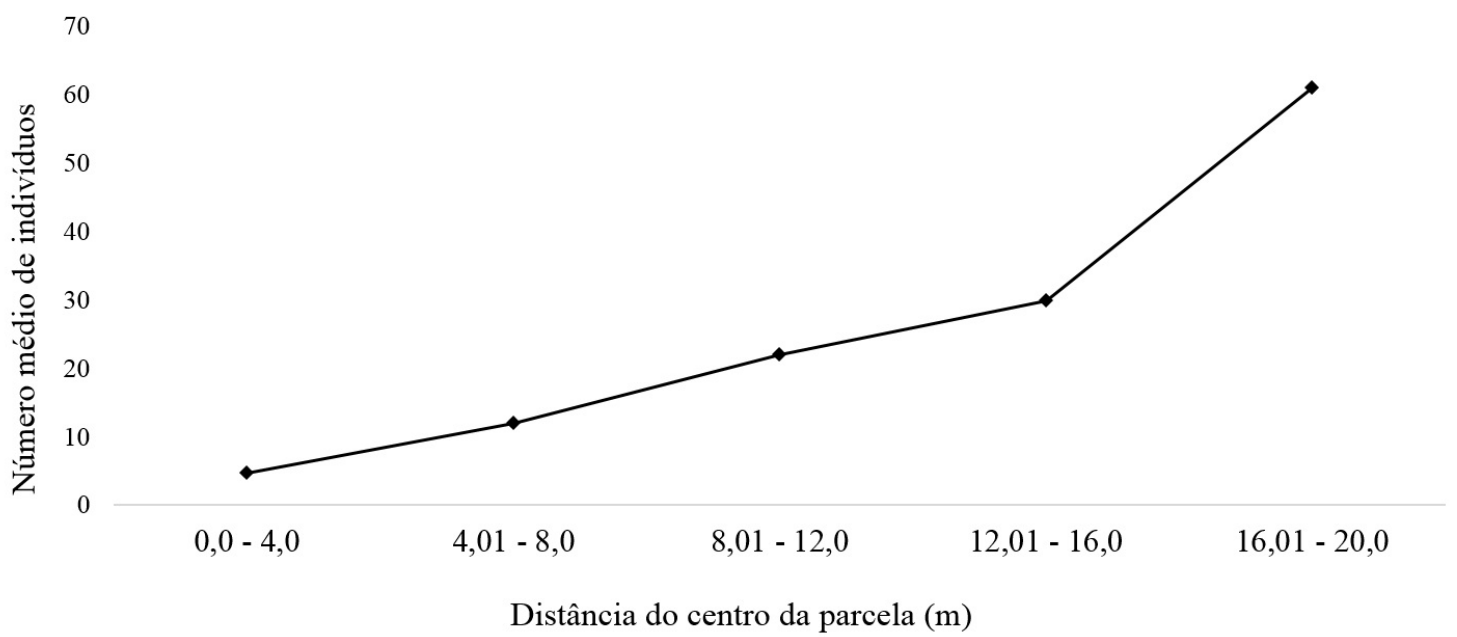

FIGURA 2: Distância da regeneração natural da Ocotea odorifera em relação ao centro da parcela na RPPN Uru, Lapa, Paraná, Brasil.

FIGURE 2: Distance of natural regeneration of Ocotea odorifera in the plot center in PNHR Uru, Lapa, Paraná state, Brazil. 
1970. Observado também para outras espécies arbóreas, como Araucaria angustifolia e Campomanesia xanthocarpa (NASCIMENTO; LONGHI; BRENA, 2001), o padrão agregado é caracterizado pela formação de manchas, indicando que a espécie ocorre em locais semelhantes dentro da área de estudo, seguindo as especificidades e exigências para a manutenção da população, ou seja, a possibilidade de ocorrência de um indivíduo é aumentada pela presença de outro. O conhecimento do padrão de distribuição é considerado a chave para a solução dos problemas típicos das florestas tropicais, pois fornece informações que podem ser utilizadas na identificação de possíveis especificidades quanto a fatores ambientais, além de fornecer informações sobre os mecanismos e dispersão e regeneração, subsidiando o desenvolvimento de pesquisas conservacionista (BARROS; MACHADO, 1984).

Ao todo foram identificados $909(44,7 \%)$ indivíduos enquadrados na classe Juvenil I - 0 a $0,50 \mathrm{~m}$ de altura; 759 (37,3\%) na classe Juvenil II - 0,51 a 1 m; 260 (12,8\%) na classe Juvenil III - 1,01 a 1,5 m; e $105(5,2 \%)$ na classe Juvenil IV - 1,5 a $2 \mathrm{~m}$ de altura (Figura 3).

As populações naturais apresentam dois padrões distintos de crescimento, que podem ser combinados ou alternados de acordo com as características da população e principalmente do meio (ODUM, 1988). A forma $\mathrm{S}$ ou sigmoide é representada pelas oscilações atenuadas entre as classes de idade e a forma $\mathrm{J}$ é característica de organismos que apresentam oscilações bruscas em sua distribuição etária (BOTREL et al., 2002).

O padrão de crescimento observado para a regeneração natural de Ocotea odorifera na presente pesquisa tende para uma forma exponencial negativa, caracterizada como J-invertido, em que é constatada maior abundância na classe Juvenil I e um decréscimo regular nas classes, conforme o aumento da amplitude em altura, o que é considerado um padrão para as florestas estáveis e com idade e composição de espécies variadas (RODE et al., 2010; RESENDE et al., 2012; DALMASO et al., 2013). Embora a maior quantidade de indivíduos pertencentes a classes etárias menores possa sugerir que a perpetuação da espécie está garantida, a capacidade de competição dentro do nicho ecológico é um fator imprescindível para a

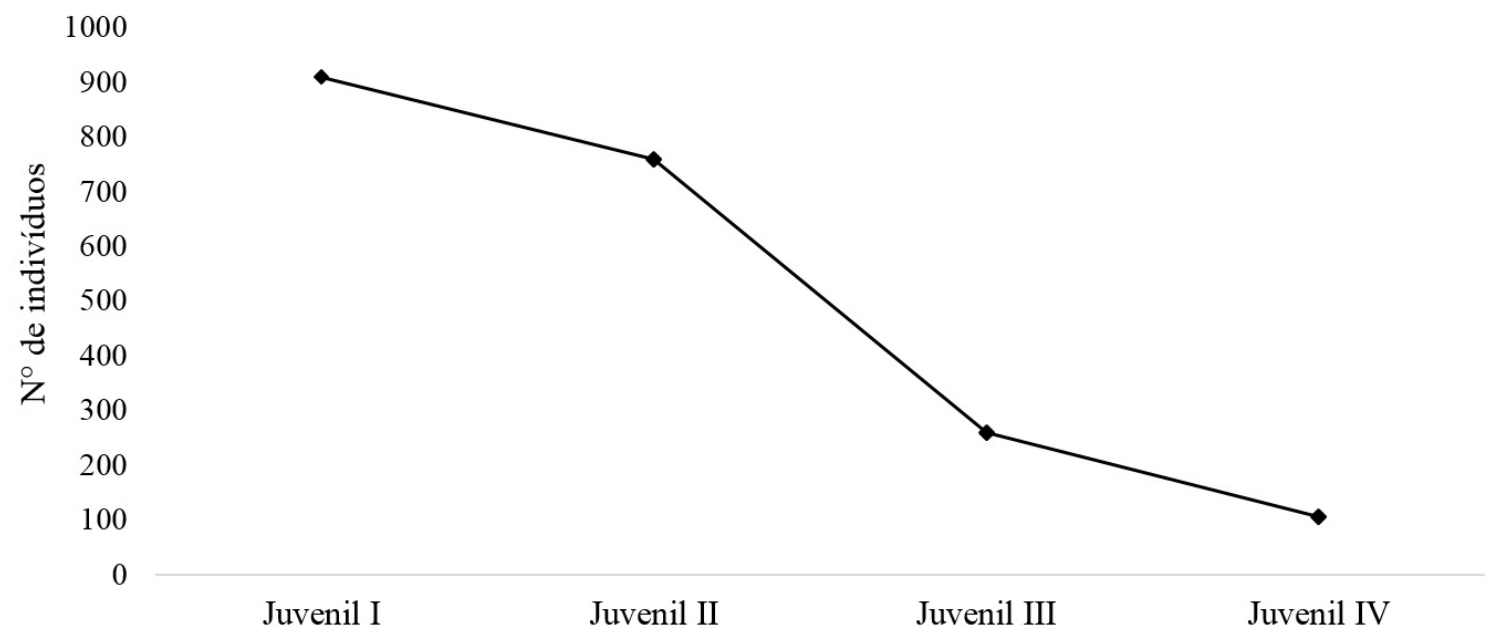

Classes etárias

FIGURA 3: Frequência de indivíduos de Ocotea odorifera pertencentes às classes etárias I, II, III e IV $(\mathrm{N}=2033)$.

FIGURE 3: Frequency of individuals of Ocotea odorifera belonging age groups I, II, III and IV $(\mathrm{N}=2.033)$. 
manutenção das populações (MACHADO et al., 2010). Isso pode explicar a diminuição da abundância nas classes de tamanho superior, determinando a estrutura etária da população observada. O padrão J-invertido foi observado para populações de Ocotea odorifera (CETNARSKI-FILHO; NOGUEIRA, 2004; DALMASO et al., 2013), Ocotea porosa (CALDATO; LONGHI; FLOSS, 1999), Matayba elaeagnoides (LINGNER et al., 2007), Araucaria angustifolia (RIBEIRO et al., 2013), e outras espécies características da Floresta Ombrófila Mista.

O modelo de distribuição tipo J-invertido sugere que a população apresenta um quadro de estabilidade e autorregeneração, existindo um equilíbrio entre a mortalidade e o recrutamento de novos indivíduos (SOUZA; SOUZA; MEIRA NETO, 2012). A abundância de indivíduos jovens representa uma estratégia adaptativa que garante a continuidade temporal da espécie no ambiente, mas para que isso ocorra, deve ser capaz de promover a manutenção de sua população por meio de uma grande produção de sementes, taxa de germinação satisfatória e mortalidade decrescente (RESENDE et al., 2012). O ciclo reprodutivo de Ocotea odorifera é caracterizado pela irregularidade, o que reflete em uma produção inconstante de sementes, que somado à necessidade da associação com fungos micorrízicos restringe ainda mais suas possibilidades de desenvolvimento.

\section{CONCLUSÕES}

A regeneração natural de Ocotea odorifera na RPPN Uru esteve concentrada nas áreas de Floresta Ombrófila Mista em estágio avançado de sucessão e a espessura da serapilheira influenciou na abundância dos regenerantes. Houve acréscimo da população, conforme aumento da distância da árvore-matriz central e o padrão de crescimento observado foi o J-invertido, comum a populações estáveis que apresentam potencial de regeneração constante. O padrão de distribuição foi tipo agregado, caracterizado pela ocorrência em grupos, formando manchas de acordo com as exigências e especificidades de desenvolvimento da espécie. Pelas características apresentadas, a população estudada de Ocotea odorifera mostrou estar em equilíbrio com o ambiente local; sendo o elevado número de regenerantes juvenis I e II, um possível indicativo da estratégia adaptativa que garante a continuidade temporal da espécie no ambiente avaliado.

A implantação de estratégias que objetivem a perpetuação da espécie nos fragmentos de Floresta Ombrófila Mista remanescentes indica a importância do desenvolvimento de pesquisas que permitam o reconhecimento das possibilidades e potencialidades ecológicas da Ocotea odorifera, especialmente quanto a sua capacidade regenerativa.

\section{REFERÊNCIAS}

BARROS, P. L. C.; MACHADO, S. A. Aplicação de índices de dispersão em espécies de florestas tropicais da Amazônia brasileira. Curitiba: FUPEF, 1984. 44 p. (Série Científica I).

BOTREL, R. T. et al. Influência do solo e topografia sobre as variações da composição florística e estrutura da comunidade arbóreo-arbustiva de uma floresta estacional semidecidual em Ingaí, MG. Revista Brasileira de Botânica, São Paulo, v. 25, n. 2, p. 195-213, 2002.

BRASIL. Ministério do Meio Ambiente. Corredores ecológicos: experiências em planejamento e implementação. Brasília: MMA, 2007. 58 p.

BRASIL. Ministério Do Meio Ambiente. Lista oficial das espécies da flora brasileira ameaçadas de extinção. 2014. Disponível em: <www.ibama.gov.br>. Acesso em: 20 dez. 2014.

BROCARDO, C. R.; CÂNDIDO JÚNIOR, J. F. Persistência de mamíferos de médio e grande porte em fragmentos de Floresta Ombrófila Mista no Estado do Paraná, Brasil. Revista Árvore, Viçosa, MG, v. 36, p. 301-310, 2012.

BROTTO, M. L.; CERVI, A. C.; SANTOS, E. P. O gênero Ocotea (Lauraceae) no estado do Paraná, Brasil. Rodriguésia, Rio de Janeiro, v. 64, n. 3, 2013.

CALDATO, S.; LONGHI, S. J.; FLOSS, P. A. Estrutura populacional de Ocotea porosa (Lauraceae) em uma Floresta Ombrófila Mista, em Caçador (SC). Ciência Florestal, Santa Maria, v. 9, n. 1, p. 89-101, 1999.

CARVALHO, P. E. R. Canela-sassafrás. 2005. Disponível em: <http://www.infoteca.cnptia.embrapa.br/ 
handle/doc/288823>. Acesso em: 16 nov. 2014. (Circular Técnica).

CASTEllA, P. R.; BRITEZ, R. M. A. A floresta com araucária no Paraná: conservação e diagnóstico dos remanescentes florestais: Projeto de Conservação e Utilização Sustentável da Diversidade Biológica Brasileira - PROBIO. Brasília: MMA, 2004. 236 p.

CASTELLANI, D. C. et al. Produção de óleo essencial em canela (Ocotea odorifera Vell.) e guaçatonga (Casearia sylvestris Swartz) em função da época de colheita. Revista Brasileira de Plantas Medicinais, Paulínia, v. 8, n. 4, p. 104-107, 2006.

CETNARSKI-FILHO, R.; NOGUEIRA, A. C. Influência da temperatura na germinação de diásporos de Ocotea odorifera (Vellozo) Rohwer (Canela-sassafrás). Ciência Florestal, Santa Maria, v. 15, n. 2, p. 191198, 2005.

CETNARSKI-FILHO, R.; NOGUEIRA, A. C. Regeneração natural de Ocotea odorifera (Vell.) Rohwer (canela-sassafrás). Revista Acadêmica: ciências agrárias e ambientais, Curitiba, v. 2, n. 3, p. 61-68, 2004. CENTRO DE REFERÊNCIA EM INFORMAÇÃ̃O AMBIENTAL. Ocotea odorifera. Disponível em: <www.cria.org.br>. Acesso em: 02 ago. 2014.

DALMASO, C. A. et al. Padrões espaciais na regeneração de Ocotea odorifera na Floresta Nacional de Irati, PR. Floresta, Curitiba, v. 43, n. 2, p. 301-312, 2013.

FRANKE, C. R. et al. Mata Atlântica e biodiversidade. Salvador: EDUFBA, 2005.

GALINDO-LEAL, C.; CÂMARA, I. G. Mata Atlântica: biodiversidade, ameaças e perspectivas. São Paulo: Fundação SOS Mata Atlântica, 2005. 20 p.

IBGE. Manual técnico da vegetação brasileira. 2. ed. Rio de Janeiro: IBGE, 2012.

INSTITUTO AMBIENTAL DO PARANÁ. Lista Oficial de espécies da flora ameaçadas de extinção no Estado do Paraná. 2008. Disponível em: <http://www.iap.pr.gov.br>. Acesso em: 10 set. 2014.

INSTITUTO BRASILEIRO DE FLORESTAS. Mata Atlântica, 2014. Disponível em: < http://www. ibflorestas.org.br>. Acesso em: 15 set. 2014.

INSTITUTO CHICO MENDES DE CONSERVAÇÃO DA BIODIVERSIDADE. Plano de Manejo da Reserva Particular do Patrimônio Natural Uru. Curitiba: ICMBIO, 2014. 320 p.

JANZEN, D. H. Herbivores and the number of tree species in tropical forests. The American Naturalist, Chicago, v. 104, n. 940, p. 501-528, 1970.

KOZERA, C. et al. Espécies vasculares de uma área de campos naturais do sul do Brasil em diferentes unidades pedológicas e regimes hídricos. Revista Brasileira de Biociências, Porto Alegre, v. 10, n. 3, p. 267-274, 2012.

LEITE, P. F.; KLEIN, R. M. Vegetação. In: IBGE. Geografia do Brasil: Região Sul. Rio de Janeiro: IBGE, 1990. p. 113-150.

LINGNER, D. V. et al. Caracterização da estrutura e da dinâmica de um remanescente de Floresta com Araucária no Planalto Catarinense. Pesquisa Florestal Brasileira, Colombo, n. 55, 2007.

LORENZI, H. Árvores Brasileiras: manual de identificação e cultivo de plantas arbóreas nativas do Brasil.

5. ed. São Paulo: Instituto Plantarum, 2008. v. 1.

LORENZI, H.; MATOS, F. J. A. Plantas Medicinais no Brasil: nativas e exóticas. São Paulo: Instituto Plantarum, 2002.

MACHADO, E. L. M. et al. Flutuações temporais nos padrões de distribuição diamétrica da comunidade arbóreo-arbustivo e de 15 populações em um fragmento florestal. Revista Árvore, Viçosa, MG, v. 34, n. 4, p. 723-732, 2010.

MULLER-DOMBOIS, D.; ELLENBERG, H. Aims and methods of vegetation ecology. New York: John Wiley \& Sons, 1974.

MYERS, N. et al. Biodiversity hotspots for conservation priorities. Nature, London, v. 403, p. 853-858, 2000.

NASCIMENTO, A. R. T.; LONGHI, S. J.; BRENA, D. A. Estrutura e padrões de distribuição espacial de espécies arbóreas em uma amostra de Floresta Ombrófila Mista em Nova Prata, RS. Ciência Florestal, Santa Maria, v. 11, n. 1, p. 105-119, 2001.

NASCIMENTO, N. A.; CARVALHO, J. O. P.; LEÃO, N. V. M. Distribuição espacial de espécies arbóreas relacionadas ao manejo de florestas naturais. Revista Ciência Agrária, Belém, n. 37, p. 1-20, 2002.

OBRZUT, V. V.; CARVALHO, R. I. N. Utilização do óleo essencial de sassafrás para o manejo da mariposa

Ci. Fl., v. 27, n. 2, abr.-jun., 2017 
oriental em pessegueiro. Revista Acadêmica de Ciências Agrárias, Curitiba, v. 9, n. 1, p. 65-71, 2011. ODUM, E. P. Fundamentos de ecologia. 4. ed. Lisboa: Fundação Calouste Gulbenkian, 1988. 927 p. PALUDO, G. F.; MANTOVANI, A.; REIS, M. S. Regeneração de uma população natural de Araucaria angustifolia (Araucariaceae). Revista Árvore, Viçosa, MG, v. 35, n. 5, p. 1107-1119, 2011.

PEREIRA, J. N. et al. Relationships between microbial activity and soil physical and chemical properties in native and reforested Araucaria angustifolia forest in the state of São Paulo, Brazil. Revista Brasileira de Ciências do Solo, Viçosa, MG, v. 37, p. 672-686, 2013.

QUINET, A. et al. Lauraceae in Lista de Espécies da Flora do Brasil. Rio de Janeiro: Jardim Botânico do Rio de Janeiro, 2014. Disponível em: <www.floradobrasil.jbrj.gov.br>. Acesso em: 8 dez. 2014.

QUINET, A.; ANDREATA, R. H. P. Lauraceae Jussieu na Resera Ecológica de Macaé de Cima, Município de Nova Friburgo, Rio de Janeiro, Brasil. Rodriguésia, Rio de Janeiro, v. 53, p. 59-121, 2002.

RESENDE, I. L. M. et al. Estrutura etária de populações de Mauritia flexuosa L. F. (Arecaceae) de veredas da região central de Goiás, Brasil. Revista Árvore, Viçosa, MG, v. 36, n. 1, p. 103-112, 2012.

RIBEIRO, T. M. et al. Fitossociologia de uma Floresta Secundária com Araucaria angustifolia (Bertol.) O. Kuntze na Estação Ecológica de Bananal, Bananal-SP. Floresta e Ambiente, Seropédica, v. 2, n. 20, p. 159-172, 2013.

RODE, R. et al. Estrutura horizontal da comunidade arbórea sob um povoamento com Araucaria angustifolia e uma Floresta Ombrófila Mista. Pesquisa Florestal Brasileira, Colombo, v. 30, n. 64, p. 347-361, 2010.

SALM, R. Arborescent palm seed morphology and seedling distribution. Brazilian Journal of Biology, São Carlos, v. 4, n. 65, p. 711-716, 2005.

SANTA-CATARINA, C.; MACIEL, S. C.; PEDROTTI, E. Germinação in vitro e embriogênese somática a partir de embriões imaturos de canela sassafrás (Ocotea odorifera Mez). Revista Brasileira de Botânica, São Paulo, v. 24, n. 4, p. 501-510, 2001.

SANTOS, M. M. G. et al. Chuva de sementes de espécies lenhosas florestais em mosaico de floresta com Araucária e campos no Sul do Brasil. Acta Botanica Brasilica, Belo Horizonte, v. 1, n. 25, p. 160-167, 2011.

SILVA, W. C. et al. Estudo da regeneração natural de espécies arbóreas em fragmento de Floresta Ombrófila Densa, Mata das Galinhas, no Município de Catende, Zona da Mata Sul de Pernambuco. Ciência Florestal, Santa Maria, v. 17, n. 4, p. 321-331, 2007.

SOUZA, P. B.; SOUZA, A; L.; MEIRA NETO, J. A. A. Estrutura diamétrica dos estratos e grupos ecológicos de uma área de Floresta Estacional Semidecidual, em Dionísio, MG. Revista Árvore, Viçosa, MG, v. 36, n. 1, p. 151-160, 2012.

VAN GROENENDAEL, J. M.; BULLOCK, S. H.; PEREZ-JIMENEZ, L. A. Aspects of the population biology of the gregarious tree Cordia elaegnoides in Mexican Tropical Deciduous Forest. Journal of Tropical Ecology, Cambridge, v. 12, n. 1, p. 11-24, 1996.

VENTUROLI, F.; FELFILI, J. M.; FAGG, C. W. Avaliação temporal da regeneração natural em uma Floresta Estacional Semidecídua Secundária, em Pirenópolis, Goiás. Revista Árvore, Viçosa, MG, v. 35, n. 3, p. 473-483, 2011.

ZAÚ, A. S. Fragmentação da Mata Atlântica: aspectos teóricos. Floresta e Ambiente, Seropédica, v. 5, n. 1, p. 160-170, 1998. 